\title{
SUBSTANTIATION OF FIELD OF APPLICATION OF COMBINED (TRADITIONAL AND PHYSICAL- AND-CHEMICAL) GEOTECHNOLOGIES FOR THE DEVELOPMENT OF GRAVEL AND SECONDARY GOLD DEPOSITS
}

\author{
Artur Sekisov ${ }^{1 *}$, Anna Rasskazova ${ }^{1}$, Alexandr Lavrov ${ }^{2}$ and Roman Bogomyakov ${ }^{1}$ \\ ${ }^{1}$ Mining Institute of Far eastern branch of Russian Academy of Sciences, Khabarovsk, Russia \\ ${ }^{2}$ Transbaikal State University, Russia.
}

\begin{abstract}
Problems of accumulation of technogenic tailings dumps and as a result of sluicing of gold sands of gravel deposits are considered in article. Additional recovery of fine and dispersed gold from a mineral mass of such technogenic formations can be carried out with use of physical and chemical geotechnologies. The factors influencing on the choice of a way of development of the gold gravel deposit are listed. The mathematical model of a gravel deposit is developed for the solution of the problem of multifactorial assessment of technological options of processing of gold sands. The scheme of the combined development of the gravel gold deposit is offered. Cuvette gold leaching experiments with the photo-electro activated solutions on various reagent basis were executed for the assessment of a developed scheme. Material for the researches was a gravity concentrate (schlich) fraction obtained by tailings gravity concentration (Kia gravel deposit, Transbaikal Territory). The first stage of gravity concentrate (schlich) processing included contacting with photoelectro activated carbonaceous solution $\left(\mathrm{NaHCO}_{3}\right)$. The first leaching reagent scheme (cyanide solution concentration of $1.5 \mathrm{~g} / 1$ prepared on the basis of photo-electro activated the peroxide - carbonaceous solution provided $66.8 \%$ gold extraction. The second reagent scheme (active chloride-carbonaceous solution) provided $88.9 \%$ gold extraction.
\end{abstract}

\section{Introduction}

The Russian Far East or Far East Russia (FER) is host to a huge gold endowment and has produced more than $6500 \mathrm{t}$ of gold, since the 1860s. Much of this gold has come from several mining districts: Aldan, Upper Amur, Lower Amur, Okhotsk, Allakh-Yun, YanaKolyma, Priokhotie, Omolon, and Chukotka. These districts include several gold deposits, mostly of orogenic and epithermal nature, as well as large and very large alluvial placer

*Corresponding author: sekisovag@mail.ru 
deposits [1]. The Priamur province is one of the main gold-bearing provinces of Russia with the level of gold ore (about 180 tons) and placer (about 1132 tons) gold [2].

The effectiveness of development of large-scale gravel gold deposits is defined by the establishment of efficient field of use of open, underground and physical and chemical ways of their development. It is caused by the essential variation of mining-and-geological parameters in the plan and for depth of the deposit. Some of large-scale gravel deposits can extend to tens of kilometers. An example of such object is an alluvial in a Kruchina river valley (Transbaikal Territory). Development of this alluvial deposit lasts for more than 100 years (with breaks) with use of dragging, bulldozer ways of open-cast mining and locally underground development is applied. Nowdays one site of this alluvial deposit is planned to development by well (in-situ) leaching. Depth of high-grade layer of gold sands is $18 \mathrm{~m}$. Secondary mineral formations (tailing dumps and tailings of gold sands sluicing) are accumulated in the result of a long-term development of gravel gold deposits. Residual content of precious metal can be comparable with gold content in sections of the deposit near to cutoff grade. In these mineral formations gold is presented by fine-grained, nanodimensional and encapsulated mode of occurrence. A range of micro-analytical and microbiological techniques is applied for the research of thin gold-rich gravel within bedrock gravity traps, hosting elongated and flattened placer gold particles coated with manganese-, iron-, barium- (Mn-Fe-Ba) oxide crusts. These crusts host abundant nanoparticulate and microcrystalline secondary gold, as well as thick biomats [3]. Post-mining placer deposits include tailings, overburden rocks, and non-mined spaces over the mining area (polygon) sides and in its bottom, and all this is a rock mass with its gold grades ranging from 0.12 to $0.26 \mathrm{~g} / \mathrm{m}\left(^{3}\right)$ to be all reprocessed using modern equipment and advanced technologies. Non-extracted gold differs by its morphology ranging from fine and rather thin platy to coarse native and quartz-aggregated type [4]. Reprocessing of mineral mass of secondary mineral formations, as well as development of deep-laying sites of a gravel deposit and between-pit pillar can be economically, efficiently and ecologically safely carried out with use of physical and chemical geotechnologies.

Sands of gravel deposits are an important source of gold and other valuable heavy minerals, in particular, of an ilmenite, titanomagnetite, zircon, monocyte and rutile [5]. The combination of a gravitational method of mineral processing with amalgamation is traditional for small deposits. Mercury, a dangerous pollutant, is the preferred method employed by small-scale miners for gold recovery. Gold extraction using mercury is comprised of the following four stages: (1) amalgamation, (2) separation of amalgamation, (3) removal of excess mercury, and (4) burning of the remaining amalgam to produce a gold sponge. Mercury can be released into the environment at each stage, which makes the promotion of mercury-free alternatives imperative [6]. It is also possible to reach increase in effectiveness of gravitational processing of gold sands by means of preliminary reagent processing of mineral mass [7].

Therefore, the choice of a way, an order and parameters of development of sites of an alluvial deposit with various conditions of bedding of gold sand layers, their geometrical and structural parameters, has to be solved together with problems of development of secondary mineral formations, and taking into account a time factor.

\section{Mathematical modeling of mining operations (variation of the main ways and parameters of development of alluvial deposit sites, gold sands processing and technogenic mineral mass)}

Estimation of quantity and quality of reserves of productive gold sands (by unproven and/or operational blocks) is necessary for the choice of a way of development of sites of the gold 
alluvial deposit and/or field of use of combined development. Multifactorial calculations of parameters of excavation (open pit or cuvettes) can be made taking into account their possible combination with physical and chemical geo-technologies or the subsequent use when involving in development of refractory and hard-cleaning sands. The modern mathematical models of deposits are formed as the numerical matrixes setting space and qualitative parameters of geometrized mineral bodies and bearing strata. Geometrical and qualitative parameters of separate components can be set as initial parameters. Coordinates of wells with the interval indication of the useful and harmful elements concentration can be set as initial parameters too. On the basis of initial data, borders of the homogeneous sites of mineral bodies are automatically defined. Considering not determined character of geological data, it was offered to map divide contours in inter-well space on the basis of expected and statistical determination of coordinates of transitional (between high-grade and low-grade) mineralized zones. This method was designed in Moscow Geological Prospecting Institute (MGPI) in 1983 [8]. The main geostatistical method of outline (drilling out) is Gaussian Process Regression Model. One dividing line between projections of wells with the shift from the center is mapped according this method. Two dividing lines are mapped according MGPI method. The contour of the expected transition zone with the corresponding order of metal content is defined. Values of gold content for the main boundary zones are replaced from concrete values to statistically average for the corresponding category of alluvial sand. Besides the formal selection of zones on value of content of gold (grade) in them characteristics (morphology and the gold particles size, existence of dispersible forms of finding of gold, the sand defining its extraction at enrichment technogenic (technogenic transformed) raw materials (or leaching), existence in it of the accompanying industrially valuable components is considered mineralogical-andgeochemical [9]. Assessment of stocks of secondary deposits is an important point in the choice of technology of development. There are indirect methods of assessment of stocks of technogenic resources, providing essential simplification of calculation of stocks, thus simplifying technology of development of secondary deposits [10].

For the solution of the problem of multifactorial assessment of effectiveness of technological parameters of production and processing of gold sands, the mathematical model of the gravel deposit has to be spontaneous and autocorrected. For this purpose, the initial information which is based on data of detailed geological prospecting, in process of drilling and approbation of wells, has to be renewed periodically. At the same time comparison of the preliminary and earlier specified contours of the industrial mineralization is carried out. Correction of industrial mineralization contours is carried out. The histogram of gold distribution in different fractions is fulfilled. Modes of gold occurrence (free, encapsulated and dispersible gold) are taken into account too.

Setting of rational sequence of mining operations and parameters of pits (cuvettes) can be provided by mathematical models. Mathematical models include economic, and technological criteria, directly or indirectly reflecting the current value and future gold prices. Retrospective dynamics of the prices, an order and parameters of formation and secondary processing of natural and technogenic mineral material have to be considered in the modern computer models.

Duration of development of large-scale and average gravel deposits, variation of morphological-structural and real parameters of productive layers, specification of volumes of overburden rock and low-grade sands should be considered in the process of modeling. As a result, different positions of front of strip mine; variant of productive blocks (with various morphological-structural characteristics and qualitative characteristics of sands) development; ways of gold sand and tailings processing are obtained. Criterion of the choice of efficient option of development of mining operation is the quantity of extracted gold (from primary and secondary sources). The maximal size of gold production $\left(\boldsymbol{P}_{\boldsymbol{A} u}\right)$ 
index will define an optimal variant. This criterion is compound and is expressed by the following formula (1):

$$
\begin{aligned}
\mathrm{P}_{\mathrm{Au}}=\sum_{i=1}^{N} \sum_{j=1}^{M} h \cdot S \cdot \bar{c}_{i j} & \mathrm{~K}_{\text {ore }} \mathrm{K}_{\min } \mathrm{K}_{\mathrm{proc}} \cdot \frac{\mathrm{P}_{\mathrm{yj}}}{\mathrm{E} \cdot\left(1+\mathrm{q}_{\mathrm{s}} \cdot \mathrm{n} \cdot \mathrm{Z}_{\mathrm{q}}\right)}+\left(1-\mathrm{K}_{\min } \mathrm{K}_{\text {ore }}\right) \mathrm{K}_{\mathrm{ml}}{ }^{y} \cdot \mathrm{T} \cdot \mathrm{K}_{\text {extr }} \cdot \frac{\mathrm{P}_{\mathrm{yj}}}{\mathrm{E}^{\prime}}+ \\
& \left.+\left(1-\mathrm{K}_{\text {ore }} \cdot \mathrm{K}_{\min } \cdot \mathrm{K}_{\text {proc }}\right) \cdot \mathrm{K}_{\mathrm{ml}}^{\prime} \cdot \mathrm{T} \cdot K_{\text {extr }} \cdot \frac{P_{\mathrm{yj}}}{\mathrm{P}^{\prime \prime}}\right] \rightarrow \max ,
\end{aligned}
$$

where $i, j$ - the index of the ore blocks and a type of the valuable component in alluvial sand respectively;

$\mathrm{N}$ and $\mathrm{M}$ - the number of the indexed ore blocks and types of a valuable component respectively;

h, S - height of a bench (terrace), $\mathrm{m}$ and the area of the ore block, sq.m;

$\overline{\boldsymbol{c}}_{\mathrm{ij}}-\boldsymbol{j}$-component content in $\boldsymbol{i}$-block $\left(\mathrm{g} / \mathrm{m}^{3}\right)$;

$\mathrm{K}_{\text {ore }}, \mathrm{K}_{\min }, \mathrm{K}_{\text {proc }}$-ore-bearing coefficient, coefficient of mining extraction and processing extraction (and/or gold leaching from the remained pillar between pit or cuvettes) respectively, as a decimal fraction;

$\mathrm{P}_{\mathrm{yj}}$ - cost price (expected) of $\mathrm{j}$-component in $\mathrm{y}$-year, rub;

E, E', E" - overall expenses of production for balance reserves, off-balance alluvial sands, tailings of sluicing (and/or gold leaching from the remained pillar between pit/cuvette), rub; $\mathrm{K}_{\mathrm{ml}}{ }^{\mathrm{y}}, \mathrm{K}_{\mathrm{ml}}^{\prime}{ }^{\mathrm{y}}$ - coefficients of migration losses from tailing dumps of primary processing and secondary gravity concentrate processing plant tailings in y-year, as a decimal fraction;

$\mathrm{T}$ - period of assessment, years;

$K_{\text {extr }}, K_{\text {extr }}^{\prime}$ - coefficients of metal extraction for the secondary processing by traditional and geotechnological methods respectively from tailings of sands sluicing, as a decimal fraction;

$\mathrm{q}_{\mathrm{s}}$ - gradient of an increase of the area of overburden as a result of increase in peat depth for the definite block, as a decimal fraction;

$\mathrm{n}$ - number of overburden benches over i-block;

$\mathrm{Z}_{\mathrm{q}}$ - share of mining costs in the common structure of expenses, as a decimal fraction.

The offered criterion $\left(\boldsymbol{P}_{A u}\right)$ allows to carry out the choice of rational options of development of mining operations and formation and involvement in secondary operation of technogenic formations in the uniform system of mathematical models.

\section{Substantiation of the combined flow-sheet of gravel deposit development}

When the order of development of a gravel deposit and the field of use of traditional and physical-chemical geotechnologies are established by results of model operation, it is necessary to organize a rational technical communication inside the corresponding flow diagram. Authors propose to combine traditional and geotechnological methods by multipurpose application of mine excavations. This approach can be carried out as follows.

First prospecting and assaying takes place. Delineation of high-grade in gold content sites (blocks) of the gravel deposit is carry out by the results of assay. Then drainage channels are constructed on the borders of blocks. After overburden has been removed, alluvial gold sand is mined by excavator. Pits (small cuts, cuvettes) are formed by bulldozer. The pits (cuvettes) are isolated with the dense waterproof film on the bottom. Tailings (pulp) from gravitational sluice comes to the equipped pits. Rough gravity concentration tailings contain fine fraction with not-extracted fine and lamellar gold. Tailings of processing of rough gravity concentrate are loaded in isolated pits (cuvettes) 
too. Rough gravity concentrate is processed in cleaner gravity concentration industrial equipment. Excess water is pumped out and returned to washing of gold sand after mineral particles sedimentation in the pit. Inlet wells are additionally drilled inside between-pit pillar. Wells are tubed and filters are installed inside. Leaching solutions containing active oxidizers are injected to productive layer of gold sands. First them iron and manganese are leached from sands. Then gold leaching solutions is injected to the productive layer after a technological pause. Leaching solutions containing active oxidizers and gold leaching solutions drained through productive layer of alluvial deposit. Pregnant solution after the filtration is accumulated in pits (cuvettes) for oxidation of dumped fine fraction of sands washing tails and gravity concentrate (schlich) fraction. Then gold is leached from this mixture. Cuvette leaching of residual gold from tailings of gravity concentration is carried out from the sands extracted by the traditional way.

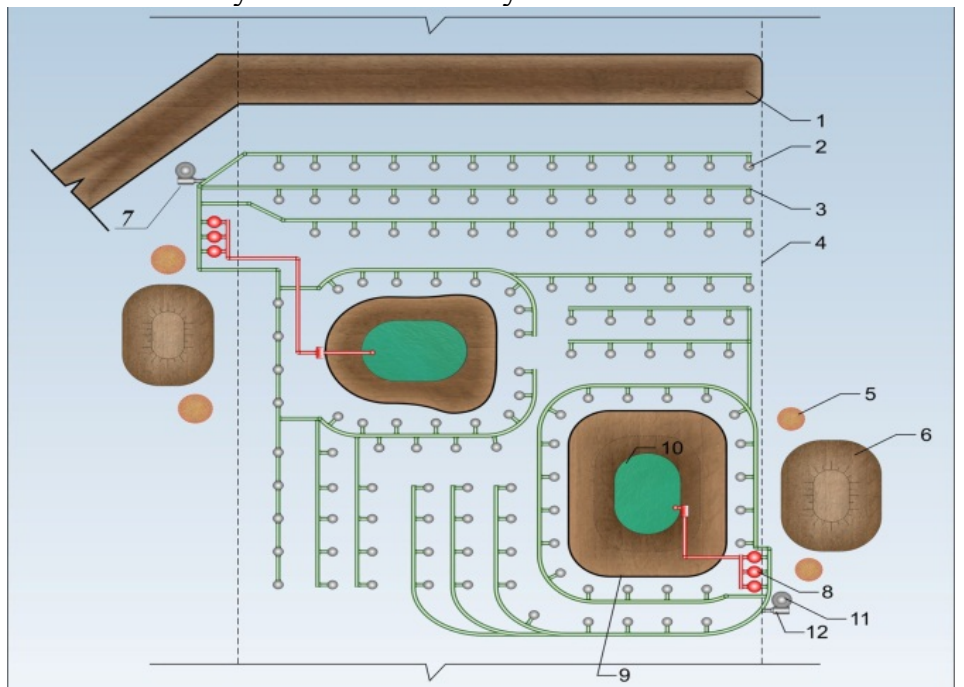

Fig. 1. The flow-sheet of the combined development of the gravel gold deposit.

1. Drainage channel. 2. Inlet wells. 3. Pipeline. 4. Block border. 5. Tails of sand washing. 6. Tailing dumps. 7. Pump. 8. Sorption columns. 9. Pit (cuvettes). 10. Receiver pond 11. Reagent container 12. Pump-measuring bin.

Samples of recirculating oxidizing and pregnant solutions are periodically analyzed for divalent iron, manganese, and gold. Solutions are recirculated and injected to productive layer in case of iron, manganese, and gold content are lower than the threshold. Active solutions provide the required extent of oxidizing preparation of mineral weight and additional gold recovery. Injection of the gold leaching solutions containing the active oxidizers in a layer is begun after the end of circulation through productive layer and cuvette. When threshold concentration of gold is reached, productive solutions accumulated in cuvettes are pumped out to sorption columns. The starved solutions are strengthened and pumped to inlet wells. When gold content is decreased in pregnant solutions down to lower threshold value, mineral mass in cuvettes is pulped by irrigation with this solution. Gold should be adsorbed form the leaching solution first and solution strengthened up to working reagent concentration. The pregnant solutions received in cuvette are pumped to sorption columns. In case of processing of pulped mineral weight, sorption leaching of gold is applied in the cuvette. Application for the Russian Federation patent was applied for this method of combined development of gold-bearing gravel deposit and tailing dumps processing (No. 2018109621, 19.03.2018). 


\section{Experimental Technique and materials}

Cuvette leaching experiments were executed on mineral material of Kia gravel deposit. Magnetite containing gravity concentrate (schlich) fraction of tailings of sands concentration was applied as a research material. Photo-electro activated solutions with various reagent basis were used. The possibility of use of the combined method of development of a gravel deposit with the high gold content in gravity concentrate (schlich) was assessed by results of the experiment. Gold losses reach 55\% in mining enterprise developing Kia gravel deposit. More than a half of losses are bound to the compact-grained magnetite of gravity concentrate (schlich) which is washed away with tailings in the gold sands processing.

Gold extraction experiments from magnetite by active leaching solutions were made as follows. The first sample of gravity concentrate (schlich, $2 \mathrm{~kg}$ ) with $143.5 \mathrm{ppm}$ gold content was placed in a cuvette and contacted with photo-electro activated carbonaceous solution $(500 \mathrm{ml})$. The retention time was 1 month. After iron hydrooxides appeared on magnetite surfaces, carbonaceous solution was deleted. The second stage is characterized by different reagent regime. First is cyanide leaching $(1.5 \mathrm{~g} / \mathrm{l})$ on the basis of photo-electro activated peroxide-carbonaceous solution. Second is leaching of gravity concentrate (schlich, $2 \mathrm{~kg}$ ) with $175 \mathrm{ppm}$ the gold content by active chloride and carbonaceous solution. The active chloride and carbonaceous solution prepared as follows. The photo-electro activated solution prepared on the basis of sodium bicarbonate solution with sodium peroxide was mixed with hypochlorite solution and conditioned with hydrochloric acid till $\mathrm{pH}=6.8-7.1$. Also, as well as in the first cuvette, 5 cycles of a leaching were carried out.

\section{Results and discussion}

Data, demonstrating gold recovery to pregnant solution are given in figure 2 .

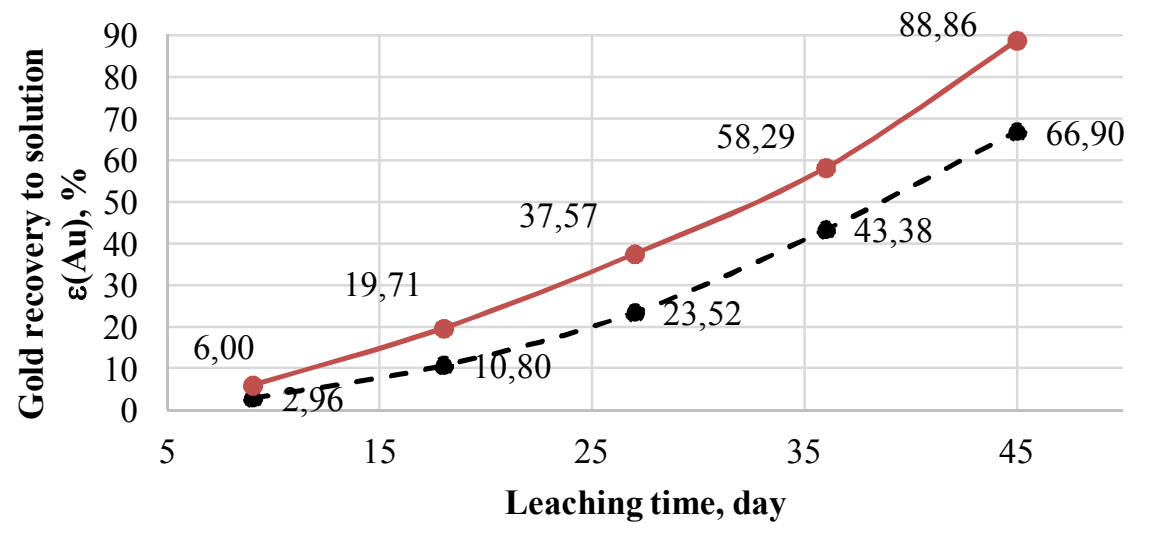

\section{- - Carbonate-cyanide reagents (1 mounth carbonate preparation) —Chloride-carbonate reagents (1 mounth carbonate preparation)}

Fig. 2. A kinetics of gold leaching from gravity concentrate (schlich, Kia gravel deposit)

As a result of carbonate-cyanide leaching $66.8 \%$ of gold was extracted for 2.5 months. As a result of chloride-carbonate leaching $88.9 \%$ of gold was recovered for the same period. Chloride provide faster leaching kinetics and higher gold recovery to pregnant solution the cyanide-based solution. Preparation of mineral mass by active carbonate solution provided peroxidation and preparation of mineral mass for leaching. 


\section{Conclusions}

Secondary processing of mineral mass of secondary formations and development of deeplaying sites of a gravel deposit and between-pit pillar is a current problem of the modern mining industry. The mathematical model of the gravel deposit is developed for the assessment of the factors influencing the choice of efficient option of development of mining operations and key parameters of development of gravel deposit and processing of productive sands. Authors also offered the combined technology of development of the gravel gold deposit including a well leaching of gold from deep-laying productive layers and a cuvette leaching of gold from washing tailings, provides efficient extraction of fine and dispersible gold. Experiments on a two-stage cuvette leaching of gold from a gravity concentrate (schlich) of Kia gravel deposit are made. The initial gold content in gravity concentrate (schlich) is $143-175 \mathrm{~g} / \mathrm{t}$. Duration of the first stage was 1 month. Test was processed by the photo-electro activated carbonaceous solution. Processing of a gravity concentrate (schlich) by carbonaceous peroxide solution provided oxidation of iron to iron hydroxide. The second stage was carried out accoarding two reagent modes. A cyclic leaching (1.5 months) was made by the cyanide solution $(1.5 \mathrm{~g} / \mathrm{l})$ prepared on the basis of photo-electro activated the peroxide-carbonaceous solution according the first reagent flowsheet. Gold recovery is $66.8 \%$ for cyanide-carbonate solution. The active chloride and carbonaceous solution has provided $88.9 \%$ gold extraction for the same period. It is experimentally proved that processing of gravity concentrate (schlich) material of gravel deposits can be economically efficiently and it is carried ecologically safely out with use of physical and chemical geotechnologies.

\section{Acknowledgement}

The research was carried out with the support of scientific grant "Development of technology of cyanide-free leaching of refractory gold from low-grade copper and porphyritic ores" provided by the Government of Khabarovsk Territory under the contract No. 115/2018D, 28.06.2018.

\section{References}

1. N. A. Goryachev, F. Pirajno, Ore Geology Rev. 59, pp. 123-151 (2014).

2. V. A. Stepanov, A. V. Melnikov, J. of Mining Inst. 87, pp. 5-12 (2015).

3. E. B. Melchiorre, P. M. Orwin, F. Reith 87, (2018).

4. Y. Pruss, $12 \mathrm{~h}$ International Multidisciplinary Scientific Geoconference (SGEM) I, pp. 627-629 (2012).

5. J. Wierchowiec, Gospodarka Surowcami Mineralnymi-Mineral Resources Management 87, pp. 133-147 (2008).

6. R. Vieira, J. of Cleaner Production 87, pp. 448-454 (2006).

7. T. N. Aleksandrova, A. V. Aleksandrov, N. M. Litvinova, J. of Mining Science 87, pp. 319-325 (2013).

8. A.G. Sekisov, S.A. Piskunov, B.L. Filatov Patent, Russian Federation, 2044877, Method of excavation of ore intended for leaching, 11.05.95

9. V.N. Oparin, A.G. Sekisov, A.I. Trubachev, B.N. Smolyanitsky, V.S. Salikhov, N.V. Zykov, J. of Mining Science 3, pp. 70-78 (2017).

10. B. L. Talgamer, International Conference on Innovations and Prospects of Development of Mining Machinery and Electrical Engineering (IPDME) 87 (2017). 